E6-2009-194

N. V. Aksenov ${ }^{1}$, G. A. Bozhikov, G. Ya. Starodub, S. N. Dmitriev, D. V. Filosofov, Jon Sun Jin, V. I. Radchenko, N. A. Lebedev, A. F. Novgorodov

\title{
ANION EXCHANGE BEHAVIOR OF Ti, Zr, Hf, Nb AND Ta AS HOMOLOGUES OF Rf AND Db IN MIXED HF-ACETONE SOLUTIONS
}

Submitted to the Book of Proceedings by American Institute of Physics (Conference Proceeding) of the EXON-2009 Symposium, September 28October 2, 2009, Sochi, Russia

${ }^{1}$ E-mail: nikolay.aksenov@jinr.ru 


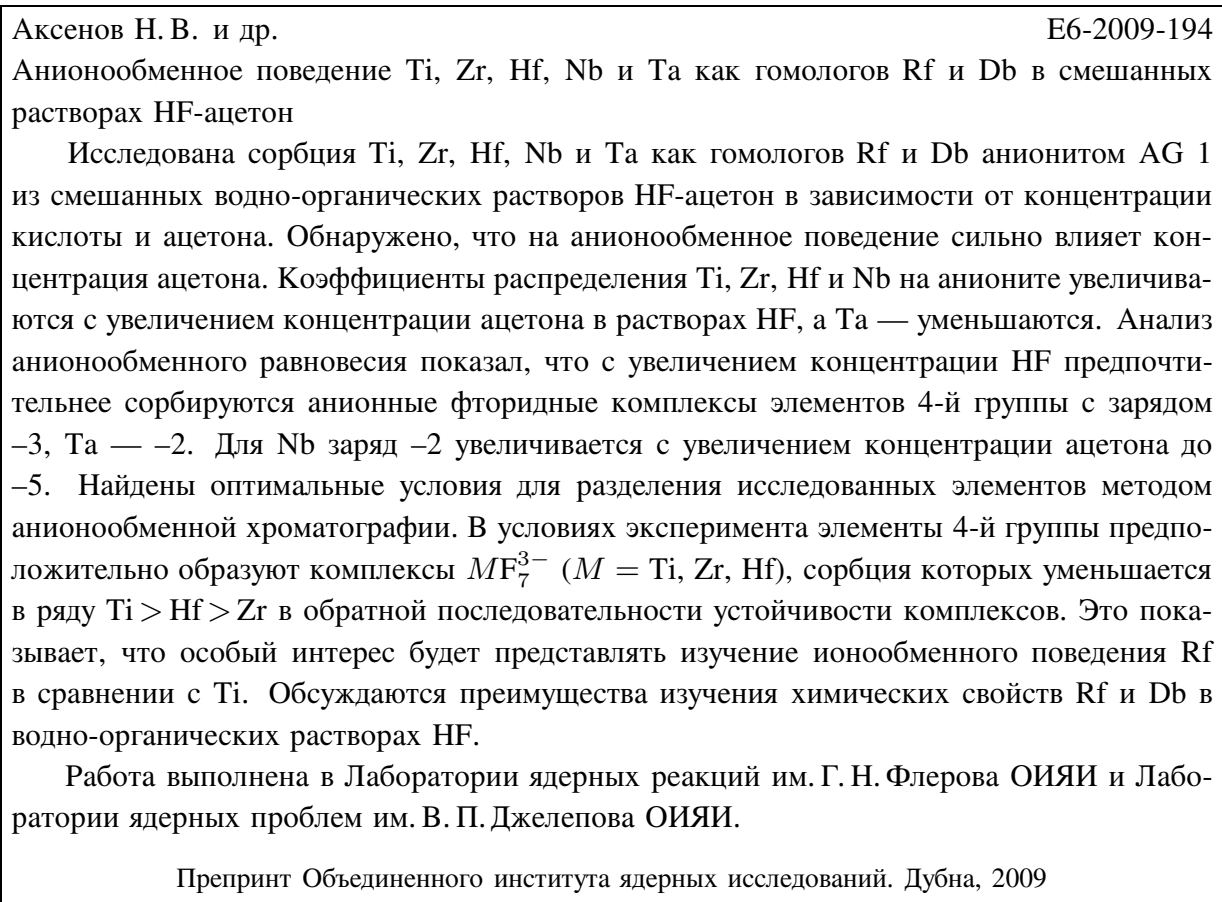

Aksenov N. V. et al.

Anion Exchange Behavior of Ti, Zr, Hf, $\mathrm{Nb}$ and $\mathrm{Ta}$ as Homologues of Rf and $\mathrm{Db}$ in Mixed HF-Acetone Solutions

We studied in detail the sorption behavior of $\mathrm{Ti}, \mathrm{Zr}, \mathrm{Hf}, \mathrm{Nb}$ and $\mathrm{Ta}$ on $\mathrm{AG} 1$ anion exchange resin in HF-acetone mixed solutions as a function of organic cosolvent and acid concentrations. Anion exchange behavior was found to be strongly acetone concentration dependent. The distribution coefficients of $\mathrm{Ti}, \mathrm{Zr}, \mathrm{Hf}$ and $\mathrm{Nb}$ increased and those of $\mathrm{Ta}$ decreased with increasing content of acetone in HF solutions. With increasing HF concentration, anion exchange equilibrium analysis indicated the formation of fluoride complexes of group- 4 elements with charge -3 and $\mathrm{Ta}$ with charge -2 . For $\mathrm{Nb}$ the slope of -2 increased up to -5 . Optimal conditions for separation of the elements using AIX chromatography were found. Group-4 elements formed $M \mathrm{~F}_{7}^{3-}(M=\mathrm{Ti}, \mathrm{Zr}$, Hf) complexes whose sorption decreased $\mathrm{Ti}>\mathrm{Hf}>\mathrm{Zr}$ in reverse order of complex stability. This fact is of particular interest for studying ion exchange behavior of Rf compared to Ti. The advantages of studying chemical properties of Rf and $\mathrm{Db}$ in aqueous HF solutions mixed with organic solvents are briefly discussed.

The investigation has been performed at the Flerov Laboratory of Nuclear Reactions, JINR, and Dzhelepov Laboratory of Nuclear Problems, JINR. 


\section{INTRODUCTION}

Chemical identification of radionuclides in the decay chains of the recently discovered transactinide elements may serve as a method for confirming the discovery [1]. The longer half-lives of radionuclides of transactinides discovered in the $\mathrm{An}+{ }^{48} \mathrm{Ca}$ reactions make possible the application of radiochemical techniques for their chemical characterization in solutions [2]. In previous experiments, an ion exchange method combined with $\mathrm{Db}$ fluoride complexation was used [3,4]. It is well known that ion exchange in water-miscible organic solvents exhibits more effective separation of metal ions [5]. To optimize conditions for isolation and study of chemical properties of Rf and $\mathrm{Db}$, we investigated anion exchange behavior of their lighter homologues in groups 4 and 5 respectively, from HF-acetone mixed solutions. In addition, the influence of organic cosolvent on fluoride complexation and behavior in concentrated HF solutions of these elements were also examined. The sorption behavior of $\mathrm{Ti}, \mathrm{Zr}, \mathrm{Hf}, \mathrm{Nb}$ and $\mathrm{Ta}$ on $\mathrm{AG} 1$ anion exchanger in aqueous-organic solutions of $\mathrm{HF}$ as a function of organic cosolvent and acid concentrations was studied in detail.

\section{EXPERIMENTAL METHODS}

All the chemical reagents used were of analytical grade. The concentration of the initial HF solution was checked by titration with freshly prepared standard $\mathrm{KOH}$ solutions. Anion exchange resin AG $1 \mathrm{X} 8\left(\mathrm{Cl}^{-}\right.$form, $200-400$ mesh) was purchased from Fluka Chemika. Prior to use, the resin was washed with distilled water and then converted to $\mathrm{F}^{-}$form by washing with $2 \mathrm{M} \mathrm{HF}$. After that the resin was air-dried in an oven at $60^{\circ} \mathrm{C}$ for 24 hours and samples of $100 \mathrm{mg}$ each were weighed. HF-acetone mixed solutions were prepared by weighing required quantity of acetone to HF solutions and bringing to final volume with distilled water. The volume of the samples was $1 \mathrm{~cm}^{3}$ of mixed solution.

We used radionuclides ${ }^{44} \mathrm{Ti},{ }^{88} \mathrm{Zr},{ }^{181} \mathrm{Hf},{ }^{92} \mathrm{Nb}$ and ${ }^{182} \mathrm{Ta}$ which were produced at JINR facilities. ${ }^{182} \mathrm{Ta}$ and ${ }^{181} \mathrm{Hf}$ were obtained from neutron-irradiated metallic forms of ${ }^{181} \mathrm{Ta}$ and ${ }^{180} \mathrm{Hf}$ (IBR-2 FLNP). Irradiated targets of ${ }^{181} \mathrm{Ta}$ and ${ }^{180} \mathrm{Hf}$ were dissolved in mixed conc. HF- $0.5 \mathrm{M} \mathrm{HNO}_{3}$ and conc. HF solution, respectively. ${ }^{88} \mathrm{Zr}$ and ${ }^{92} \mathrm{Nb}$ prepared by irradiation of $\mathrm{Sr}$ and $\mathrm{Y}$ (natural isotope abundance) with $\alpha$ particles (initial energy $35 \mathrm{MeV}, \mathrm{He}^{+}$beam current $\sim 10 \mu \mathrm{A}$, 
exposure time 4 hours) on U-200 accelerator (FLNR). Production and radiochemical purification of ${ }^{88} \mathrm{Zr}$ were performed as described in [6] and for ${ }^{92} \mathrm{Nb}$ by analogy with [7].

${ }^{44} \mathrm{Ti}$ was produced in spallation reactions of $\mathrm{Cu}$. Irradiated metallic copper (660 $\mathrm{MeV}$ protons at the phasotron (DLNP)) was dissolved in conc. $\mathrm{HNO}_{3} .3 \mathrm{mg}$ $\mathrm{Fe}$ in the form of a $\mathrm{Fe}\left(\mathrm{NO}_{3}\right)_{3}$ solution was added and the hydroxide precipitated with concentrated ammonia solution. Under these conditions ${ }^{44} \mathrm{Ti}$ coprecipitates and $\mathrm{Cu}$ and most of nuclear reactions products $(\mathrm{Co}, \mathrm{Ni}, \mathrm{Zn})$ remain in solution. For separation of ${ }^{44} \mathrm{Ti}$ from $\mathrm{Fe}$ and radionuclides of $\mathrm{Mn}, \mathrm{Cr}, \mathrm{V}, \mathrm{Sc}$ cation exchange chromatography in $\mathrm{HCl}$ solutions was used. The $1 \mathrm{ml}$ stock solution, containing no carrier added ${ }^{44} \mathrm{Ti},{ }^{88} \mathrm{Zr},{ }^{92} \mathrm{Nb}$ and $10 \mu \mathrm{g} \cdot \mathrm{ml}^{-1}{ }^{180} \mathrm{Hf}$ and ${ }^{181} \mathrm{Ta}$ each, was prepared with a $20 \mathrm{M} \mathrm{HF}$.

A series of batch experiments were performed at room temperature in order to determine distribution ratio of $\mathrm{Ti}, \mathrm{Zr}, \mathrm{Hf}, \mathrm{Nb}$ and $\mathrm{Ta}$ between mixed HF-acetone solutions and AG 1 anion exchanger. In all experiments the solid to solution ratio was $10 \mathrm{~cm}^{3} \cdot \mathrm{g}^{-1}$. Prepared solutions and resin were added into Eppendorf tubes and samples were left for 2 days in order to reach equilibrium. After that the samples were centrifuged for 10 minutes and aliquots from supernatant were taken. Amounts of element adsorbed onto resin were determined from the difference between radioactivity in solution before and after the equilibration time. Gamma-spectrometric determination of radionuclides was performed using a $\mathrm{Ge}$ detector from Ortec having energy resolution of $1.5 \mathrm{keV}$ for the ${ }^{60} \mathrm{Co} \gamma$-quantum energy at $1.33 \mathrm{MeV}$ and coupled to a multichannel analyzer from Ortec.

Values of the distribution coefficient $\left(K_{d}, \mathrm{ml} \cdot \mathrm{g}^{-1}\right)$ of $\mathrm{Ti}, \mathrm{Zr}, \mathrm{Hf}, \mathrm{Nb}$ and $\mathrm{Ta}$ in AG 1 - HF-acetone mixed solutions system were published in [8].

\section{RESULTS AND DISCUSSION}

The obtained results let us make some conclusions about complexation and mechanism of sorption of group- 4 and 5 elements in HF-acetone mixed solutions. The influence of acetone on sorption behavior of studied elements can be seen in Fig. 1.

Such behavior can be explained by two competing processes. It is known that in the concentrated $\mathrm{HF}$ solution formation of $\mathrm{HF}_{2}^{-}$is predominant [9]. Thus, ion exchange equilibrium of fluoride complexes could be represented by the following chemical reactions:

$$
\begin{gathered}
R_{n} M \mathrm{~F}_{4+n}+n \mathrm{HF}_{2}^{-} \Leftrightarrow n R \mathrm{HF}_{2}+M \mathrm{~F}_{4+n}^{n-} \quad(M=\mathrm{T} i, Z r, H f), \\
R_{n} M \mathrm{~F}_{5+n}+n \mathrm{HF}_{2}^{-} \Leftrightarrow n R \mathrm{HF}_{2}+M \mathrm{~F}_{5+n}^{n-} \quad(M=\mathrm{N} b, T a),
\end{gathered}
$$

where $R$ is fixed ion group of the resin. In the presence of acetone, dissociation of HF decreases as the concentration of acetone increases because the dielectric 


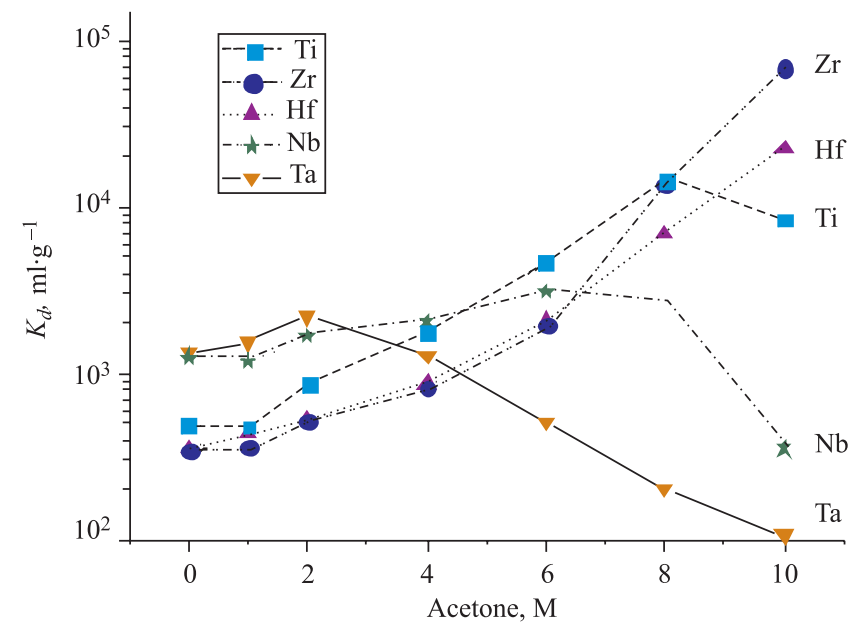

Fig. 1. $K_{d}$ values of $\mathrm{Ti}, \mathrm{Zr}, \mathrm{Hf}, \mathrm{Nb}$ and $\mathrm{Ta}$ as a function of acetone concentration for $6 \mathrm{M}$ HF (AG $\left.1 \mathrm{X} 8, \mathrm{~F}^{-}\right)$

constant of acetone is higher than that of water. As a result, the concentration of counter ion $\mathrm{HF}_{2}^{-}$decreases and sorption of fluoride complexes of $\mathrm{Ti}, \mathrm{Zr}, \mathrm{Hf}$ and $\mathrm{Nb}$ increases (Fig. 1). At acetone concentrations higher than $8 \mathrm{M}$ for $\mathrm{Nb}$, Ti and $10 \mathrm{M}$ for $\mathrm{Zr}$, formation of less negatively charged and neutral complexes takes place and sorption decreases. Influence of acetone on adsorption of Ta appears to be in the opposite direction. Effect of acetone on Ta uptake by AG 1 was found to be negligible within the interval $0-1 \mathrm{M}$. Further increasing of acetone concentration leads to a decrease in retention.

Effect of increasing HF concentration in mixed HF-acetone solution on the distribution of fluoride complexes was examined and results are presented in Fig. 2. Maximum $K_{d}$ values of all the studied elements were found at HF concentration range between 0.1 and $1 \mathrm{M}$, indicating formation of strong fluoride complexes with $\mathrm{F}^{-}$ions. Further increase of $\mathrm{HF}(>2 \mathrm{M})$ concentration results in formation of the $\mathrm{HF}_{2}^{-}$counter ion and shift of ion exchange equilibrium (Eqs. (1) and (2)). Consequently the sorption of $\mathrm{Ti}, \mathrm{Zr}, \mathrm{Hf}, \mathrm{Nb}$ and $\mathrm{Ta}$ decreases at higher concentrations of $\mathrm{HF}$ due to displacement of anion complexes with the $\mathrm{HF}_{2}^{-}$ion (Fig. 2).

According to anion exchange equilibrium (Eqs. (1) and (2)), $K_{d}$ can be represented as follows:

$$
\log K_{d}=\log D-n \log \frac{\left[\mathrm{HF}_{2}^{-}\right]}{\left[R \mathrm{HF}_{2}\right]},
$$

where $D$ is the selectivity coefficient of exchanging anions, $n$ is the number of charges of anionic complexes $M \mathrm{~F}_{4+n}^{n-}$ or $M \mathrm{~F}_{5+n}^{n-}$. Results of calculation of $n$ are 


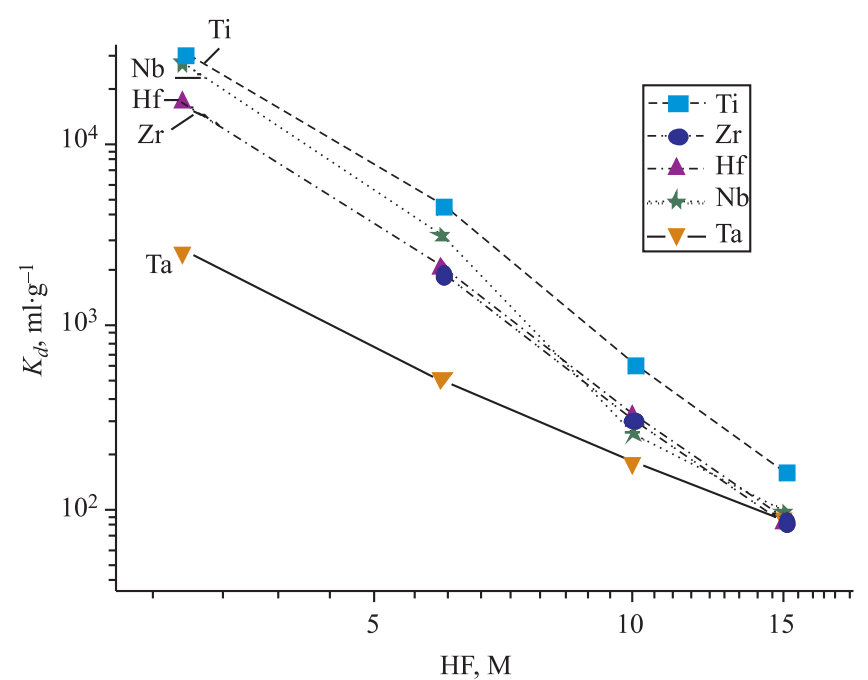

Fig. 2. $K_{d}$ values of $\mathrm{Ti}, \mathrm{Zr}, \mathrm{Hf}, \mathrm{Nb}$ and $\mathrm{Ta}$ as a function of $\mathrm{HF}$ concentration for $6 \mathrm{M}$ acetone (AG 1X8, $\mathrm{F}^{-}$)

presented in Table 1. Since we do not know concentration of $\mathrm{HF}_{2}^{-}$ions in acetonecontaining solutions, values of $n$ were calculated according to concentration of HF. Nevertheless, it can be seen that the values of $n$ calculated from $\mathrm{HF}$ and $\mathrm{HF}_{2}^{-}$ in the absence of acetone are nearly equal. The values of $n$ for $\mathrm{Ti}, \mathrm{Zr}$ and $\mathrm{Hf}$ are approximately 3, while the values of $n$ for $\mathrm{Nb}$ and Ta are approximately 2 . It should be noted that with increasing acetone concentration the values of $n$ for $\mathrm{Ti}, \mathrm{Zr}$, Hf and $\mathrm{Ta}$ increase a little and for $\mathrm{Nb}$ the value increases up to 5 .

At low $\mathrm{pH}$ and in the presence of $\mathrm{HF}$, group-4 elements are known to form anionic complexes $M \mathrm{~F}_{5}^{-}, M \mathrm{~F}_{6}^{2-}, M \mathrm{~F}_{7}^{3-}(M=\mathrm{Zr}$, Hf) [5, 10]. Therefore, it can be concluded that under the present experimental conditions $\mathrm{Ti}, \mathrm{Zr}$ and $\mathrm{Hf}$ exist in the form of $\mathrm{MF}_{7}^{3-}$ complexes. However, literature data indicates that in the presence of $\mathrm{F}^{-}$ions the dominant species in the solution is $M \mathrm{~F}_{6}^{2-}[10,11]$. We can assume

Table 1. Charges of anionic complexes of $\mathrm{Ti}, \mathrm{Zr}, \mathrm{Hf}, \mathrm{Nb}$ and $\mathrm{Ta}$ in $\mathrm{HF}$-acetone mixed solutions. Calculated from Eq. (3)

\begin{tabular}{|c|c|c|c|c|c|c|}
\hline Acetone, M & & $\mathrm{Ti}$ & $\mathrm{Zr}$ & $\mathrm{Hf}$ & $\mathrm{Nb}$ & $\mathrm{Ta}$ \\
\hline 0 & $\mathrm{HF}_{2}^{-}$ & 2.9 & 3.1 & 3.1 & 2 & 2 \\
\hline 0 & $\mathrm{HF}$ & 3.1 & 3.2 & 3.1 & 2.1 & 2.1 \\
\hline 1 & $\mathrm{HF}$ & 3.1 & 3.1 & 3.1 & 2.2 & 2.1 \\
\hline 2 & $\mathrm{HF}$ & 3.2 & 3.1 & 3.2 & 2.3 & 2.2 \\
\hline 4 & $\mathrm{HF}$ & 3.3 & 3.3 & 3.3 & 3 & 2.2 \\
\hline 6 & $\mathrm{HF}$ & 3.3 & 3.4 & 3.3 & 3.7 & 2.1 \\
\hline 8 & $\mathrm{HF}$ & & & & 5.1 & 2.4 \\
\hline
\end{tabular}


Table 2. Separation factors for the separation of $\mathrm{Nb}$ and Ta by anion exchange on the AG 1 in mixed HF-acetone solutions

\begin{tabular}{|c|c|c|c|c|c|c|c|c|c|}
\hline \multirow{2}{*}{ HF, M } & \multicolumn{10}{|c|}{ Acetone, M } \\
\cline { 2 - 11 } & 0 & 1 & 2 & 4 & 6 & 8 & 10 & 12 & 13 \\
\hline 0.5 & - & - & - & - & - & - & - & $>14$ & $>24$ \\
\hline 1 & - & - & - & - & - & $>6.5$ & $>28$ & $>51$ & 3.2 \\
\hline 3 & 1.5 & 2 & 1.5 & 3.8 & 11 & 17 & $>450$ & 4.1 & \\
\hline 6 & 0.9 & 0.8 & 0.8 & 1.6 & 6.1 & 13 & 3.3 & & \\
\hline 10 & 0.6 & 0.6 & 0.6 & 0.9 & 1.5 & 1.3 & & & \\
\hline 15 & 0.6 & 0.8 & 0.9 & 1.1 & 1.1 & & & & \\
\hline 20 & 1.4 & 1.4 & 1.4 & & & & & & \\
\hline 25 & 1.5 & 1.3 & & & & & & & \\
\hline
\end{tabular}

that at high $\mathrm{HF}$ concentration $M \mathrm{~F}_{7}^{3-}$ complexes become dominant species which preferentially adsorb on anion exchange resin and take part in sorption-desorption processes. Sorption of group-4 elements decreases $\mathrm{Ti}>\mathrm{Hf}>\mathrm{Zr}$ in reverse order of complex stability. This is in agreement with the previously reported data $[6,12]$ where, by using CIX chromatography and $\mathrm{HCl}-\mathrm{HF}$ mixed solutions, group-4 elements were separated and eluted in the order $\mathrm{Zr}>\mathrm{Hf}>\mathrm{Ti}>\mathrm{Th}$ according to fluoride complex stability constants. While in the absence of acetone, sorption of $\mathrm{Ti}, \mathrm{Zr}$ and $\mathrm{Hf}$ was found to be equal, in the presence of acetone the selectivity and order of sorption on the resin changed dramatically (Fig. 1).

Retention of $\mathrm{Nb}$ and $\mathrm{Ta}$ in the presence of acetone is more complex. In the presence of fluoride the group- 5 elements speciation is dominated by complexes $\mathrm{NbF}_{6}^{-}, \mathrm{NbOF}_{5}^{2-}, \mathrm{TaF}_{6}^{-}, \mathrm{TaF}_{7}^{2-}$ existing at different concentration of $\mathrm{F}^{-}$[13]. As shown in Fig. 1 and Table 1, in the absence of acetone $\mathrm{Nb}$ and Ta exist in the form of $\mathrm{NbOF}_{5}^{2-}$ and $\mathrm{TaF}_{7}^{2-}$, and their sorption decreases in the order of $\mathrm{Nb}>\mathrm{Ta}$. At acetone concentration higher than $2 \mathrm{M}$, anion exchange behavior of Ta becomes different from $\mathrm{Nb}$, indicating formation of not adsorbed complexes. At the same time, the mean number of charges of $\mathrm{Nb}$ anionic complexes increases.

The data presented here are of great practical interest since conditions could be found for separation of all the studied elements. Table 2 shows separation factors for $\mathrm{Nb}$ and $\mathrm{Ta}$ over the range of $\mathrm{HF}$ and acetone concentrations studied. Optimal conditions for separation of group-4 elements from each other is $6 \mathrm{M}$ $\mathrm{HF}-10 \mathrm{M}$ acetone and from group-5 elements is $15-25 \mathrm{M} \mathrm{HF}-1-4 \mathrm{M}$ acetone.

\section{CONCLUSIONS}

The results indicated that in concentrated $(>3 \mathrm{M})$ HF solutions containing acetone, group-4 elements formed complexes $M \mathrm{~F}_{7}^{3-}(M=\mathrm{Ti}, \mathrm{Zr}$, Hf) whose stability decreased in reverse order of sorption $\mathrm{Zr}>\mathrm{Hf}>\mathrm{Ti}$. This fact is of particular interest for studying ion exchange behavior of $\mathrm{Rf}$ compared to Ti. 
Under the same conditions, group-5 elements predominately formed complexes $\mathrm{NbOF}_{5}^{2-}$ and $\mathrm{TaF}_{7}^{2-}$ with anion exchange behavior considerably different in the presence of acetone. We found optimal conditions for separation of the elements using AIX chromatography.

Selectivity of sorption of all the studied elements in mixed solutions was found to be strongly acetone concentration dependent. This fact can be used for studying the influence of relativistic effects on complex formation of $\mathrm{Rf}$ and $\mathrm{Db}$. Using mixed solutions with high concentration of acetone will decrease time for spectrometric samples preparation by evaporation of eluate in experiments with Rf and Db.

Acknowledgments. This work was supported by the RFBR (grants No. 0703-00430-a and 09-03-12029-ofi_m) and by a grant of the Plenipotentiary of the Czech Republic to JINR.

\section{REFERENCES}

1. Dmitriev S.N., Oganessyan Yu.Ts., Utyonkov V.K., Shishkin S.V., Yeremin A.V., Lobanov Yu.V., Tsyganov Yu.S., Chepygin V.I., Sokol E.A., Vostokin G. K., Aksenov N.V., Hussonnois M., Itkis M. G., Gaggeler H.W., Schumann D., Bruchertseifer H., Eichler R., Shaughnessy D.A., Wilk P.A., Kenneally J.M., Stoyer M.A., Wild J.F. Chemical identification of dubnium as a decay product of element 115 produced in the reaction ${ }^{48} \mathrm{Ca}+{ }^{243} \mathrm{Am} / /$ Mendeleev Communications, 1, 1 (2005).

2. Oganessian Yu.Ts. Heaviest nuclei from ${ }^{48}$ Ca-induced reactions // J. Phys. G.: Nucl. Part. Phys. 34, R165 (2007).

3. Schumann D., Bruchertseifer H., Eichler R., Eichler B., Gaggeler H.W., Dmitriev S. N., Oganessian Yu.Ts., Utyonkov V.K., Shishkin S.V., Yeremin A.V., Lobanov Yu.V., Tsyganov Yu.S., Chepygin V.I., Sokol E.A., Vostokin G. K., Aksenov N. V., Hussonnois M., Itkis M. G. // Chemical procedure applied for the identification of $\mathrm{Rf} / \mathrm{Db}$ produced in the ${ }^{48} \mathrm{Ca}+{ }^{243} \mathrm{Am}$ reaction // Radiochim. Acta 93, 727, (2005).

4. Stoyer N. J., Landrum J. H. et al. // Nucl. Phys. A 787, 388 (2007).

5. Korkisch, J. Handbook of ion exchange resins: Their application to inorganic analytical chemistry. CRC Press, Boca Raton, FL (1989).

6. Aksenov N.V., Bruchertseifer H., Bozhikov G.A., Tereshatov E.E., Vostokin G.K., Starodub G. Ya., Shishkin S. V., Gaggeler H. W., Dmitriev S. N. Ion-exchange separation of $\mathrm{Zr}$ and $\mathrm{Hf}$ microamounts in dilute $\mathrm{HCl} / \mathrm{HF}$ solutions: A model system for chemical identification of Rf and study of its properties // Radiochemistry 50, 4, 381 (2008). 
7. Schumann D., Novgorodov A.F., Misiak R., Wunderlich G. Model studies for the separation and identification of element 107 (Bohrium, Bh): Ion exchange and precipitation experiments with $\mathrm{Tc}, \mathrm{Re}, \mathrm{Nb}$ and $\mathrm{Ta}$ nuclides from $\mathrm{HNO}_{3} / \mathrm{HF}$ containing aqueous sution // Radiochim. Acta 87, 7 (1999).

8. Filosofov D. V., Aksenov N. V., Jon Sun Jin, Bozhikov G.A., Radchenko V. I., Starodub G. Ya., Lebedev N. A., Novgorodov A. F., Dmitriev S. N. Ion exchange behaviour of $\mathrm{Ti}, \mathrm{Zr}, \mathrm{Hf}, \mathrm{Nb}$ and $\mathrm{Ta}$ as homologues of $\mathrm{Rf}$ and $\mathrm{Db}$ in mixed HF-acetone solutions. JINR Commun. P12-2008-204. Dubna, 2008. 14 p.

9. Butler J. N. Ionic equilibrium. Reading, Massachusets, 1964.

10. Godneva M.M., Motov D.L. Khimiya ftoristykh soedineniy zirkoniya i gafniya. Leningrad: Nauka, 1971.

11. Ignatieva L.N. // Zh. Neorgan. Khim. 39, 1720 (1994).

12. Aksenov $N$. V. Ionoobmennoe razdelenie $\mathrm{Ti}, \mathrm{Zr}$, Hf i $\mathrm{Th} \mathrm{v}$ smeshannih rastvorah $\mathrm{HCl} / \mathrm{HF}$ : modelnie eksperimenti po identifikacii sinteza i izucheniu svoistv Rf // Abstr. of the XV International Conference in Fundamental Sciences "Lomonosov-2008", Chemistry, Moscow State University, 2008, P. 543.

13. Agulyansky A. Chemistry of tantalum and niobium compounds. Elsevier (2004).

Received on December 16, 2009. 


\section{Редактор Е. И. Кравченко}

Подписано в печать 17.02.2010.

Формат $60 \times 90 / 16$. Бумага офсетная. Печать офсетная.

Усл. печ. л. 0,62. Уч.-изд. л. 0,84. Тираж 295 экз. Заказ № 56898.

Издательский отдел Объединенного института ядерных исследований 141980, г. Дубна, Московская обл., ул. Жолио-Кюри, 6.

E-mail: publish@jinr.ru www.jinr.ru/publish/ 